\title{
A construção de narrativas digitais por professores de ciências: análise de uma experiência de formação mediada pelas tecnologias
}

Vanessa Aparecida Schumann Santos*, Alessandra Rodrigues ${ }^{\star *}$, Mikael Frank Rezende Junior***

\section{Resumo}

Este estudo apresenta e analisa quatro encontros que constituíram uma experiência de formação cujo foco foi o desenvolvimento de narrativas digitais por professores de ciências de uma escola da rede particular do sul do estado de Minas Gerais, Brasil. Essa experiência formativa de produção de narrativas digitais foi organizada com o propósito de promover a reflexão dos docentes sobre o uso pedagógico das tecnologias digitais de informação e comunicação (TDICs), tendo como ponto de partida a pergunta: "Tenho um tablet. E agora?". A análise dos encontros desse processo formativo permitiu identificar a narrativa digital como um elemento motivador e promotor de reflexão na formação de professores, pois os docentes tiveram a oportunidade de compartilhar suas práticas com tecnologias, refletir sobre elas e, por vezes, alterá-las. Também, nas narrativas digitais resultantes dessa experiência, identificou-se a potencialidade de um recurso cognitivo a ser utilizado na formação continuada, mas também na inicial, de professores, apresentando-se viável e acessível para as diferentes realidades e contextos das escolas brasileiras.

Palavras-chave: Formação de professores. Narrativas digitais. Tecnologias digitais de informação e comunicação.

* Coordenadora pedagógica do Colégio Fepi e professora do Curso de Pedagogia no Centro Universitário de Itajubá. E-mail: vanessa_santos.sts@hotmail.com

* Professora adjunta da Universidade Federal de Itajubá (Unifei). Docente permanente do Programa de Pós-Graduação em Educação em Ciências da Unifei. E-mail: alessandrarodrigues@unifei.edu.br

..* Professor associado da Unifei. Docente permanente do Programa de Pós-Graduação em Educação em Ciências da Unifei. E-mail: mikael@unifei.edu.br 


\section{Introdução}

A área da Educação, diante do surgimento e da disseminação das tecnologias digitais de informação e comunicação (TDICs), tem passado por constantes mudanças, e as instituições de ensino vêm tentando oferecer, cada vez mais, uma formação mediada pelas tecnologias (ESCALANTE, 2013). No contexto brasileiro, a escola básica tenta paulatinamente se adaptar a essa realidade em busca de cumprir seu papel de formar cidadãos que sejam, além de integrantes, sujeitos críticos neste cenário digital. Entretanto, na maioria dos casos, ainda está distante de alcançar tal meta, como ilustram os dados do estudo longitudinal qualitativo que abarcou as cinco regiões brasileiras, realizado pelo Centro Regional de Estudos para o Desenvolvimento da Sociedade da Informação (CETIC.BR, 2016, p. 75):

[...] o cenário geral delineado pela pesquisa é o de um uso das TIC em sala de aula predominantemente como ilustração dos conteúdos, usualmente na forma de documentários ou vídeos. Os tablets, quando chegavam às escolas e havia conexão, também podiam ser usados como recurso para pesquisa. Outro elemento revelado pelo estudo é o fato de que a tecnologia era um elemento 'muito visível' em sala de aula - ou seja, seu uso não estava incorporado e naturalizado nas atividades do dia a dia.

Além disso, o estudo aponta que "[...] parcela significativa dos professores das escolas observadas faz uso das tecnologias de informação e comunicação (TIC) como recurso para a preparação das aulas e como apoio para a exposição em sala" (CETIC.BR, 2016, p. 74). Portanto, a utilização pedagógica das tecnologias ainda não se centra na crítica e na contextualização.

Para que seja possível à escola cumprir sua função social no que diz respeito ao uso das TDICs, voltar-se a um dos atores principais da cena escolar é essencial: o professor. É preciso investir na formação inicial docente, seguida de uma consistente formação continuada, a fim de assegurar aos professores a apropriação reflexiva dos recursos digitais. Para atender as exigências que esse novo cenário demanda, o professor precisa vivenciar experiências formativas mais próximas da realidade digital associada aos interesses pedagógicos, para que possa experimentá-la, apropriar-se dela e refletir sobre ela.

A narrativa - materializada nas histórias de vida (NÓVOA, 2013; PINEAU, 2006), nas narrativas de formação (PASSEGGI, 2011; GALVÃO, 2005), nas autobiografias (ABRAHÃO, 2004; SOUZA, 2011), nos diários de aula (ZABALZA, 2008), etc. 
- vem sendo utilizada como uma alternativa para promover uma formação atuante e significativa, em que o professor possa aprender com suas próprias experiências. Associada aos recursos digitais, a narrativa digital (ND) vem sendo utilizada e estudada sob diversas nomenclaturas e com diferentes abordagens (não necessariamente educacionais): digital storytelling (ROBIN, 2008; ROBY, 2010; CLARKE; ADAM, 2012; ROBIN; MCNEIL, 2012), narrativa multimídia (PAIVA, 2007; VASCONCELOS; MAGALHÃES, 2010; REDONDO, 2010; ARAÚJO, 2010), digital stories (XIN, 2014) e digital narratives (LOVELL; BAKER, 2009; FENTY; ANDERSON, 2016).

Especificamente na formação de professores, a ND pode tornar-se também uma ferramenta potente, incrementando o ato de narrar, promovendo a reflexão sobre a prática, desenvolvendo habilidades comunicativas e instigando a aproximação entre os professores e a tecnologia. Embora, no cenário brasileiro, ainda sejam escassos os estudos a esse respeito, os trabalhos de Bottentuit Junior, Lisbôa e Coutinho (2012), Almeida e Valente (2012), Rodrigues e Gonçalves (2014), Maddalena e Sevilla Pavón (2014) e Rodrigues (2017) apontam nessa direção.

Considerando o potencial educativo/formativo das narrativas, este artigo tem como objetivos apresentar e analisar os encontros que constituíram uma experiência de formação vivenciada por professores de ciências, detalhando e refletindo sobre a estruturação da ação formativa desenvolvida a partir da elaboração de NDs pelos docentes envolvidos.

\section{Narrativas digitais no desenvolvimento profissional de professores}

As narrativas trazem em si, historicamente, fragmentos de vida repletos de subjetividade, o que nos possibilita compreender o momento narrado pelo ponto de vista do autor. Pela narrativa, o fascínio da vida pode se materializar pela colocação do sujeito, de seus percursos, de suas expectativas, de seu olhar sobre o mundo em um lugar de destaque.

Por isso, a narração está ligada à vida, e sempre temos algo para contar. Narrar é relatar fatos e acontecimentos, reais ou imaginários, vividos por um indivíduo, envolvendo ação e movimento. $\mathrm{O}$ ato de narrar está presente desde os primórdios de nossa existência até os dias atuais e se manifesta de diversas maneiras. Pode-se, 
então, considerar que as narrativas podem funcionar como instrumentos de transmissão de saber e visão de mundo. Nesse sentido, Barthes (2013, p. 19) afirma que:

[...] a narrativa está presente em todos os tempos, em todos os lugares, em todas as sociedades; a narrativa começa com a própria história da humanidade; não há em parte alguma povo algum sem narrativa; todas as classes, todos os grupos humanos têm suas narrativas e frequentemente estas narrativas são apreciadas em comum por homens de culturas diferentes e mesmo opostas.

Barthes (2013) apresenta a narrativa como parte da história da humanidade, como representação da cultura, independente de classe ou época. A narrativa traz consigo a possibilidade de contar e recontar a história de um povo, não permitindo que esta história caia no esquecimento e eternizando-a. Narrar constitui-se, assim, como um instrumento que permite $o$ acesso a certo tipo de conhecimento, uma forma de compreender a relação com os outros, um processo fundamental de autoconhecimento, de desenvolvimento cognitivo e de percepção do real, vindo a possibilitar a compreensão da representação que o sujeito faz da realidade na qual está inserido.

Do ponto de vista da pesquisa e da construção do conhecimento, vários autores dedicam-se à questão da narrativa por diversas perspectivas: Bruner $(1991,1997)$ trata da narrativa como expressão do pensamento narrativo; Connelly e Clandinin (1995) discutem os caminhos teórico-metodológicos da investigação narrativa; Chené (1988) e Eckert-Hoff (2008), por sua vez, voltam-se à narrativa na formação de professores a partir de diferentes enfoques.

Relativamente às possibilidades atuais que os recursos digitais agregam ao narrar, são relevantes os estudos de Almeida e Valente $(2012,2014)$, que tratam da ND em contextos de formação docente e uso de tecnologias; Roby (2010), que defende que a produção de ND fornece aos alunos técnicas adicionais para fazer ligações mais profundas com os assuntos abordados nas disciplinas escolares; Faria, Faria e Ramos (2013), que apontam a contribuição das narrativas multimodais para o surgimento de leitura, escrita e habilidades digitais na educação infantil; Robin (2008) e Robin e McNeil (2012), que discutem as potencialidades e os usos educacionais das NDs.

Tendo em vista algumas dessas perspectivas, mas considerando especialmente as características da era digital em que vivemos, compreende-se que a ND convoca e mobiliza outras formas de representação do pensamento, numa cultura caracterizada por maiores participação e interatividade dos indivíduos, em que a expansão 
do digital e, em particular, a internet oferecem novos meios para dar forma a narrativas, bem como compartilhá-las e armazená-las.

De acordo com Almeida e Valente (2012, p. 59), “[...] as narrativas, que eram tradicionalmente orais ou escritas, podem ser agora produzidas com uma combinação de mídias, o que pode contribuir para que esta atividade seja muito mais rica e sofisticada". Em consonância com Almeida e Valente (2012), Rodrigues e Gonçalves (2014, p. 216) destacam que: "Na narrativa digital, produzida por meio das TDIC e numa textualidade eletrônica que é multimidiática, o sujeito pode lançar mão de uma diversidade ainda maior de recursos para se expressar".

Assim, com o avanço tecnológico, as narrativas passaram a ter novos suportes e possibilidades de formato digital, sendo possível que mesmo pessoas com domínio mais restrito das tecnologias pudessem narrar nesse formato, como apontam Bottentuit Junior, Lisbôa e Coutinho (2012, p. 193):

Durante muito tempo construir estórias digitais era tarefa exclusiva dos que detinham muitos conhecimentos em informática; no entanto, hoje em dia, diversos aplicativos da geração Web 2.0 permitem a criação de estórias ou narrativas digitais, de uma forma mais facilitada como, por exemplo: o flash, o Windows Movie Maker, o Photostory, um Web Blog, e ainda o software de apresentação digital como o Power Point.

Essa simplificação dos recursos tecnológicos, assim como sua democratização, vem possibilitando um movimento de reinvenção das narrativas, agora digitais, por meio de novas formas de compor e apresentar a escrita, com a inserção de elementos como sons, imagens, animações e diferentes recursos de design que ajudam a contar a história. A característica mais evidente da ND é o fato de que ela pode se apresentar em uma mídia que traduz muitas expressões, como é o caso da hipermídia, que permite a conexão entre diferentes recursos expressivos.

Para Almeida e Valente (2012, p. 58), “[...] a intenção de trabalhar com as ND é justamente a de explorar o potencial das tecnologias digitais de informação e comunicação (TDIC) no desenvolvimento de atividades curriculares de distintas áreas do conhecimento". De acordo com Carvalho (2008, p. 87):

[...] a construção e produção de narrativas digitais se constituem num processo de produção textual que assume o caráter contemporâneo dos recursos audiovisuais e tecnológicos capazes de modernizar 'o contar histórias', tornando-se uma ferramenta pedagógica eficiente e motivadora ao aluno, ao mesmo tempo em que agrega à prática docente o viés da inserção da realidade tão cobrada em práticas educativas. 
Diante da constante presença dos recursos tecnológicos no dia a dia, Paul (2007, p. 122) apresenta os elementos das NDs como sendo: “[...] mídia, ação, relacionamento, contexto e comunicação. A maior parte desses elementos é herdada de outras mídias, mas uma combinação exclusiva de elementos no ambiente digital permite novas possibilidades narrativas". No Quadro 1, são organizados e adaptados os elementos das NDs propostos por Paul (2007).

Quadro 1 - Exemplificação dos elementos das NDs

\begin{tabular}{|l|l|l|}
\hline \multicolumn{1}{|c|}{ Elemento } & \multicolumn{1}{|c|}{ Conceito } & \multicolumn{1}{|c|}{ Exemplo } \\
\hline Mídia & $\begin{array}{l}\text { Tipo de expressão utilizado para criar o ro- } \\
\text { teiro e os suportes da narrativa. }\end{array}$ & $\begin{array}{l}\text { Textos, fotografias, gráficos, } \\
\text { áudios, vídeos, animações, etc. }\end{array}$ \\
\hline Ação & $\begin{array}{l}\text { Refere-se a dois aspectos: ao movimento } \\
\text { do conteúdo, que pode ser dinâmico ou es- } \\
\text { tático, ativo ou passivo, e à ação que o usu- } \\
\text { ário requer para acessar o conteúdo. }\end{array}$ & $\begin{array}{l}\text { Movimento do conteúdo: uma } \\
\text { imagem dinâmica. } \\
\text { Ação do usuário: clicar em } \\
\text { algo, passar uma página, mi- } \\
\text { grar para outro ambiente. }\end{array}$ \\
\hline Relacionamento & $\begin{array}{l}\text { Tem como foco a relação entre o usuário e } \\
\text { o conteúdo. Pode-se ter conteúdo aberto } \\
\text { (permite interação do usuário) e conteúdo } \\
\text { fechado (não permite interação). }\end{array}$ & $\begin{array}{l}\text { Conteúdo aberto: blog. } \\
\text { Conteúdo fechado: livro digital. }\end{array}$ \\
\hline Contexto & $\begin{array}{l}\text { Traz o conteúdo adicional à ND, podendo } \\
\text { ser hipermidiático ou autoexplicativo. }\end{array}$ & Links \\
\hline Comunicação & $\begin{array}{l}\text { Refere-se à capacidade de se conectar com } \\
\text { os outros por meio da mídia digital. }\end{array}$ & Wikipédia \\
\hline
\end{tabular}

Fonte: elaboração dos autores com base em Paul (2007).

O Quadro 1 contribui para a compreensão das NDs na medida em que nos leva a perceber elementos que não estão presentes na narrativa tradicional. Considerando esses elementos, compreende-se que as NDs se constituem por meio de outro processo de produção textual, diferente da linearidade do texto tradicional, devido ao uso dos recursos tecnológicos atuais, podendo tornar-se, assim, uma nova ferramenta pedagógica para os professores. Elas trazem outros elementos que criam novas possibilidades para o autor contar sua história, e esses elementos possibilitam captar a subjetividade e dar voz a quem escreve por meio de uma multiplicidade mais ampla de signos. Rodrigues (2017, p. 123) afirma que:

No contexto contemporâneo, o narrar-se vem ganhando novos contornos desenhados pela efervescência e ubiquidade das TDIC. Ainda que continue passando pelo coração, propiciando a (re)significação do vivido e configurando-se com um espaço de construção subjetiva e intersubjetiva, a narrativa cada vez mais transforma e é transformada por essas tecnologias. 
Almeida e Valente (2014, p. 39) acrescentam ainda que, por meio das NDs, é possível "[...] organizar o pensamento e as informações, identificar as marcas essenciais, compreender e recriar as experiências". Assim, em situações de formação docente, as potencialidades das NDs poderiam contribuir tanto para a significação e ressignificação da experiência do professor quanto para a construção da sua identidade e a promoção de uma tomada de consciência de si e de seu desenvolvimento profissional, no momento em que narra e repensa suas práticas.

\section{Aspectos metodológicos do estudo}

\section{Contexto e sujeitos}

A experiência de formação apresentada e discutida neste artigo foi fruto de uma pesquisa envolvendo o desenvolvimento de ND por professores de ciências da educação básica. Os professores envolvidos na formação atuavam no ensino médio em uma escola de pequeno porte da rede particular de uma cidade do sul do estado de Minas Gerais, Brasil, que tem uma proposta pedagógica incentivadora do uso pedagógico das TDICs, por meio de um aparato em específico, o tablet.

Ainda que não seja o objetivo deste texto discutir políticas públicas e ações governamentais relativas à formação docente para uso das TDICs, cabe salientar que documentos oficiais brasileiros, como os Parâmetros Curriculares Nacionais para o Ensino Médio (BRASIL, 1998) e o Programa Ensino Médio Inovador (BRASIL, 2013), enfatizam a importância do uso didático de tecnologias no ensino. No que diz respeito à formação de professores para o uso das tecnologias, algumas iniciativas vêm sendo tomadas, dentre as quais, destaca-se o Programa Nacional de Formação Continuada em Tecnologia Educacional (PronInfo Integrado), proposto pelo Ministério da Educação (MEC) e voltado para o uso didático-pedagógico das tecnologias da informação e comunicação no cotidiano escolar, articulado à distribuição dos equipamentos tecnológicos nas escolas e à oferta de conteúdos e recursos multimídia e digitais oferecidos pelo Portal do Professor, pela TV Escola e DVD Escola, pelo Domínio Público e pelo Banco Internacional de Objetos Educacionais (BRASIL, 2009). Outra iniciativa ocorreu em 2012, quando o MEC anunciou um investimento para a compra de 600 mil tablets para uso dos professores do ensino médio de escolas públicas federais, estaduais e municipais pelo Projeto Educação Digital (BRASIL, 2012). 
Essas iniciativas ratificam a atualidade da proposta de formação apresentada e discutida neste artigo. As ações de produção das NDs tiveram início quando os professores - sujeitos deste estudo - se encontravam em uma fase de adaptação ao processo de inserção do tablet em suas aulas, conhecendo-o e descobrindo suas potencialidades de uso.

Na escola que foi lócus do estudo, no início do ano letivo são distribuídos tablets aos professores, que têm a guarda do equipamento durante todo o ano. No primeiro ano de funcionamento desse sistema, os professores receberam tablets para conhecerem o recurso e se familiarizarem com a nova ferramenta. Um período foi determinado para sua adaptação, então, a partir disso começou a ser estimulado pela direção o uso deste dispositivo em sala de aula.

Dentre as atividades regulares, reuniões pedagógicas bimestrais são realizadas com os professores, nas quais são feitas apresentações e discussões sobre temáticas que envolvem o uso pedagógico do tablet. Durante o primeiro ano letivo da proposta de implementação dos tablets, o sistema de ensino ofereceu encontros com os professores e a coordenação pedagógica da escola para capacitação no uso de materiais pedagógicos impressos e, principalmente, digitais. Entretanto, essa capacitação não foi suficiente para fomentar a aproximação dos docentes em relação ao tablet, tampouco para viabilizar e incentivar o uso pedagógico desse recurso de maneira consciente e com intencionalidade didática, visto que o foco da capacitação era $o$ "sistema" e não a atribuição de sentidos para o uso da tecnologia.

A esse respeito, parece relevante a afirmação de Almeida (2014, p. 29) quando defende que:

[...] é importante que o professor participe de um processo de formação na ação no qual tenha a oportunidade de explorar as TDIC em sua própria aprendizagem, identificar as contribuições dessas tecnologias ao ensino, à aprendizagem e ao currículo, utilizá-las em experiências com seus alunos, refletir sobre essas práticas à luz de fundamentos teóricos e reconstruí-las.

No ano seguinte, durante o período de adaptação e aprofundamento dos professores em relação à incorporação dos tablets em atividades didáticas cotidianas, alguns professores foram convidados a exercitar esse movimento proposto por Almeida (2014) e narrar as situações que estavam enfrentando com as TDICs por meio da produção de uma ND - o que se constituiu como a experiência de formação analisada e discutida neste artigo. 
Participaram dessa proposta três professores (que aderiram livremente à proposta de formação), identificados por P1, P2 e P3. P1 tem formação em Ciências Biológicas e Enfermagem, com pós-graduação lato sensu em Saúde Pública, e acumula 25 anos de experiência como docente. P2 tem licenciatura em Química, com mestrado e doutorado em Ciências, e é professora há oito anos. P3 tem licenciatura em Física, com mestrado em Ensino de Ciências, e cinco anos de experiência docente.

A experiência formativa de produção das NDs foi organizada a partir de encontros que objetivaram ações de natureza reflexiva. Conforme já mencionado, a temática proposta para a produção das NDs teve como foco e ponto de partida a pergunta: “Tenho um tablet. E agora?". A proposição dessa questão inicial teve como objetivo orientar os participantes em relação ao recorte da ND a ser elaborada, na tentativa de responder ao questionamento inicial.

Os encontros ocorreram durante quatro meses consecutivos, com um encontro mensal, cujos objetivos são apresentados a seguir.

a) Encontro 1 - conhecer os sujeitos participantes da formação; apresentar os conceitos sobre narrativa e ND; expor os possíveis formatos e recursos digitais para a elaboração da ND; apresentar o tema para dar início à narrativa: "Tenho um tablet, e agora?".

b) Encontro 2 - analisar o recurso digital escolhido pelos sujeitos da pesquisa; identificar as dificuldades e as facilidades encontradas pelos sujeitos na elaboração da ND; fazer apontamentos e direcionamentos para a narrativa não perder o foco; discutir sobre as práticas realizadas em sala de aula; socializar e refletir sobre o andamento das NDs.

c) Encontro 3 - fazer apontamentos e direcionamentos sobre o foco da narrativa; discutir sobre as práticas realizadas em sala de aula; socializar e refletir sobre $o$ andamento das NDs.

d) Encontro 4 - apresentar a ND elaborada; socializar as experiências em sala de aula; comentar sobre a experiência de criar a ND.

\section{Coleta e análise dos dados}

Os dados que dão sustentação às análises apresentadas neste texto foram coletados durante os encontros. Esse registro foi possível por meio da gravação em vídeo dos encontros e de notas de campo feitas pelos pesquisadores envolvidos. 
Cabe informar que o objetivo central da pesquisa não era analisar o processo de formação. Contudo, dada a riqueza de possibilidades que se apresentou a partir da dinâmica instituída nos encontros, essa análise tornou-se possível aproximando-se da perspectiva teórico-metodológica da "pesquisa-formação", que requer, dos sujeitos envolvidos no processo, "[...] autorizar-se, perceber-se criador de um saberfazer que é sempre práxis, ou seja, uma ação de um sujeito que se transforma ao transformar o mundo" (RIBEIRO; SANTOS, 2016, p. 297).

O olhar analítico para os dados é, portanto, qualitativo, entendendo que, por esse ponto de vista, é essencial reconhecer as perspectivas dos participantes e sua diversidade, a reflexividade do pesquisador e da própria pesquisa, assim como a variedade de abordagens e métodos possíveis (FLICK, 2009).

\section{Professores de ciências em processo de construção de narrativas digitais: análise dos resultados}

Analisando os encontros e sua dinâmica, salienta-se a importância de, no primeiro encontro, ter sido realizada uma dinâmica acolhedora de apresentação dos sujeitos. Além de ser a base para o início de qualquer trabalho formativo que considere a subjetividade dos envolvidos como elemento central, esse acolhimento inicial é (e também o foi na formação analisada) indispensável para o estabelecimento de uma relação de empatia e confiança entre os envolvidos na formação bem como para que esses sujeitos sintam-se seguros para contar suas histórias e mostrar seus medos, anseios, dificuldades, embates e conquistas, sem se sentirem julgados e/ou avaliados de qualquer forma.

Após conhecer um pouco melhor os sujeitos, a proposta de produção das NDs foi apresentada, antecedida por uma explanação a respeito do que são narrativas e NDs, que os professores começariam a elaborar. Conceitos, exemplos de narrativas e recursos tecnológicos disponíveis para sua elaboração foram apresentados, a fim de auxiliar os docentes nesse processo de criação.

Em seguida, foi proposto um primeiro exercício narrativo oral e feito durante este encontro, a partir da relação "Eu e a tecnologia". Essa recuperação mnemônica das experiências pessoais dos professores com as tecnologias em diferentes esferas da vida teve como objetivo, além de iniciar o exercício do narrar-se, enfatizar a percepção de que nossas experiências passadas constituem o que somos e como agimos 
no presente. Vários aspectos das histórias contadas nesse momento inicial foram incorporados às NDs produzidas pelos professores - denotando a percepção destes sobre a relação dialética entre passado e presente e a importância dessa relação para a formação com as tecnologias. A partir disso, foi solicitado aos professores que escolhessem um suporte digital para iniciarem a produção das NDs tendo como eixo central da história a pergunta: "Tenho um tablet, e agora?".

A escolha do suporte e dos recursos utilizados foi aberta, pois se admitiu os diferentes níveis de apropriação da tecnologia que os professores possuíam. Sendo assim, cada um recorreu ao recurso/suporte que se sentisse mais confortável e confiante para utilizar. Além disso, o aparato tecnológico foi entendido e utilizado como uma ferramenta cognitiva (JONASSEN, 2007) capaz de expandir a capacidade intelectual de seus usuários (WESTON; BAIN, 2010), e não como um fim em si mesmo. Nesse momento, notou-se um intenso envolvimento dos sujeitos na busca por um recurso adequado e motivador, bem como a satisfação ao ter autonomia para escolher - 0 que corrobora a importância desse encaminhamento durante a formação e associa-se diretamente às ideias de Almeida e Valente (2011, p. 50) sobre a apropriação da tecnologia para uso pedagógico, quando os autores afirmam que:

A formação do professor [...] envolve muito mais do que provê-lo com conhecimento técnico sobre as TDIC. Ela deve criar condições para o professor construir conhecimento sobre os aspectos computacionais; compreender as perspectivas educacionais subjacentes aos softwares em uso [...] e entender por que e como integrar o computador com o currículo e como concretizar esse processo na sua prática pedagógica.

No segundo encontro, os professores socializaram suas experiências compartilhando, pela exposição das NDs iniciadas, a relação deles com a tecnologia, desde a infância até os dias atuais, narrando algumas situações vivenciadas. Neste encontro, em que os professores começaram a apresentar o início das suas NDs, foram feitos apontamentos no sentido de incentivar a construção de uma narrativa na qual a autoria fosse privilegiada. Foi necessário instigar os sujeitos a se autorizarem à escrita de si, num exercício de reconhecimento e autorreconhecimento autoral (RODRIGUES, 2011, 2017).

Ainda neste encontro, algumas reflexões feitas pelos professores durante a produção da ND sobre suas experiências pedagógicas com o tablet começaram a aparecer e foram também discutidas no grupo - esse movimento de trazer ao coletivo as angústias e reflexões feitas individualmente durante a elaboração da ND 
começou a traçar os contornos de uma formação coletiva e colaborativa, abrindo espaços também para as individualidades e subjetividades. Cada um à sua maneira, os professores narraram momentos em família em frente ao televisor preto e branco, comentaram sobre os cursos de datilografia, o fascínio em ganhar um celular com tela verde; um momento de nostalgia os envolveu durante a produção dessa parte da ND; dessa forma, eles conduziram e dividiram suas histórias, refletindo sobre elas e, em alguns momentos, até problematizando-as em relação à docência.

Em se tratando de aproximação e apropriação da tecnologia, houve diversos posicionamentos dos professores, desde a inabilidade e o receio até o domínio e a curiosidade, passando ora pelo interesse ora pela desconfiança em relação ao uso (pedagógico ou não) das tecnologias digitais - o que se associa à diversidade de experiências vividas e às distintas formações dos sujeitos, o que se assemelha a cenários bastante comuns nas escolas brasileiras.

Nesse sentido, salientam-se alguns aspectos importantes a serem considerados na formação docente para o uso pedagógico das tecnologias: para viabilizar o uso de um recurso tecnológico, é preciso criar condições favoráveis para o professor se aproximar e apropriar-se desse recurso, que não pode ser visto como um empecilho ou um dificultador. Só então podem ser iniciadas ações para preparar e fomentar a inserção de recursos tecnológicos em seu cotidiano, de forma que ele consiga atribuir significado a isso. Assim, como apontam Almeida e Valente (2011, p. 50), “[...] além dos conhecimentos técnicos e pedagógicos, é necessário que os educadores entendam que as TDIC são mais do que ferramentas ou recursos para fazer tarefas mais rápidas".

Identificou-se, durante os encontros, que não havia muita afinidade dos professores com o tablet e que preferiam fazer uso de computador ou, então, não utilizar nenhuma tecnologia em suas aulas. Contudo, os sujeitos revelaram fazer uso pessoal de alguns recursos tecnológicos no dia a dia, no entanto, deparavam-se com barreiras entre o uso pessoal e o uso profissional em sala de aula. Esses comentários foram motivados pela socialização das NDs apresentadas nos encontros, e foi possível notar um início da apropriação tecnológica nos professores, pois, no segundo encontro, eles já estavam apresentando suas narrativas no formato digital e descrevendo as práticas desenvolvidas em sala de aula com o tablet. $\mathrm{O}$ fator incentivador para o uso do tablet em sala de aula foi gerar experiências para a posterior narração, reforçando 
a necessidade de aproximação com essa tecnologia - o que não havia ocorrido como decorrência da capacitação oferecida pela escola no ano anterior.

No terceiro encontro, também ocorreu a socialização das versões parciais das NDs, então já mais desenvolvidas. As reflexões, as discussões e os encorajamentos ganharam outro fôlego, uma vez que passaram a surgir dos próprios professores, e não mais somente dos formadores. Nesse sentido, a formação por meio da produção de ND aproximou-se do que propõem Almeida e Valente (2011, p. 50): uma formação que "[...] deve criar condições para que o professor saiba recontextualizar o aprendizado e a experiência vivida durante a sua formação para a sua realidade de sala de aula".

Neste encontro, notou-se que a produção das NDs havia se tornado algo prazeroso, um instrumento promotor de intensa reflexão e que, de certa forma, induzia à reflexão sobre a tecnologia e sua utilização pedagógica. Essa abertura ao inusitado e à reflexão sobre a ação docente foi narrada e, posteriormente, discutida no encontro, o que levou os professores a fazerem movimentos individuais e deliberados, que se associavam diretamente à sua necessidade de formação, mas também poderiam surgir de algo compartilhado pela narrativa de um colega.

Os professores, nesse processo de narrar, realizaram uma reflexão sobre si mesmos, suas práticas e o uso das tecnologias em sala de aula. Assim, a mudança na prática do professor para a utilização da tecnologia parece ter partido, primeiramente, da percepção da viabilidade de uso da tecnologia na disciplina em que ele atua (VALENTE, [1995?]; KENSKI, 2003) - percepção essa fomentada pelos encontros e pela produção das NDs.

Neste encontro, ainda, pelo estágio mais avançado das NDs compartilhadas, os posicionamentos quanto à tecnologia surgiram e passaram a ser repensados, de modo que foi possível notar que a apropriação da tecnologia pela produção da ND estava conduzindo os docentes a uma reflexão mais profunda sobre os próprios processos cognitivos em relação às TDICs. Esse momento de socializar as NDs, compartilhando com os demais sujeitos, levou os professores a repensarem práticas e atitudes num exercício individual, mas que contava sempre com a colaboração e a contribuição do grupo. Evidenciou-se, então, o sentido de uma formação continuada para o uso das tecnologias, entrelaçando saberes e fazeres, teoria e prática, ação e reflexão. Como defende Almeida (2004, p. 86), trata-se de uma formação que: 
[...] inter-relaciona conhecimentos teórico-educacionais, conhecimentos e habilidades no domínio da tecnologia e atitudes que promovam o desenvolvimento da prática reflexiva, da capacidade crítica, da compreensão de que cada indivíduo produz conhecimento, bem como a valorização do ser humano em sua multidimensionalidade (cognitiva, histórico-social e ecológica) e a compreensão de que todos podem se tornar agentes de mudança.

No quarto e último encontro, os professores apresentaram suas versões finais da ND. Eles recontaram suas histórias, suas práticas, e expuseram suas reflexões a respeito da tecnologia. A reflexão que a narrativa proporcionou aos professores sobre sua própria prática permitiu uma discussão fecunda sobre o emprego da tecnologia nas disciplinas escolares.

$\mathrm{O}$ uso da ND foi uma proposta que levou os professores à tentativa de romper barreiras e de inserir uma tecnologia digital móvel em suas práticas pedagógicas. Esta proposta os conduziu a uma reflexão sobre si mesmos, suas habilidades, suas limitações e seus desejos diante das tecnologias. Foi possível perceber, ainda, que a produção da ND e a sua socialização nos encontros também possibilitaram aos professores a reflexão sobre suas ações com a tecnologia, favorecendo a aproximação e a apropriação desses professores com a tecnologia.

Dessa maneira, nos encontros, foi possível notar que os professores se sentiram, paulatinamente, mais confortáveis com a proposta de narrar por meio de recursos tecnológicos, fazendo com que o momento de escrever não fosse um sacrifício inevitável, mas, sim, uma experiência prazerosa. O momento de narrar a experiência em que os professores relembravam o que aconteceu em sala de aula promoveu uma ação de formação para o uso de tecnologias, em que eles tiveram a oportunidade de reelaborar aquela prática e, muitas vezes, aperfeiçoá-la, além de ter uma melhor compreensão sobre quando o uso daquela tecnologia em questão era válido ou não.

Em outras palavras, desencadeou-se um movimento de ressignificação da tecnologia por meio da reflexão sobre a prática, feita a partir da narração dessa prática usando recursos digitais. Os professores puderam explorar as TDICs em seu próprio processo formativo e identificar as contribuições dos recursos tecnológicos para o ensinar e o aprender, numa perspectiva de formação bastante próxima daquela preconizada por Almeida (2014).

Com a produção das NDs, os professores assumiram a postura de autores de sua história e de seu trajeto profissional, promovida por reflexões constantes sobre sua trajetória, sua formação e suas ações docentes. Essa abordagem narrativa ga- 
nhou interessantes proporções, uma vez que, ao conseguir fazer com que o sujeito se declarasse, este foi um fator de mudança em sua constante formação, e isso aconteceu na medida em que o sujeito, agora autor, narrou suas vivências e passou a compreender algumas das interferências tecnológicas nos âmbitos pessoal e profissional. Consideramos que esse olhar dos professores para sua prática proporciona um olhar de autoformação, que lhes permitiu começar a compreender as atitudes e práticas em sala de aula.

Esta experiência de formação, apesar de restrita, enfatiza a real possibilidade de uso da produção das NDs como ação de formação, neste caso, a formação de professores para o uso de tecnologias. É interessante perceber que, na medida em que o professor se entende e se assume como autor, ele vai se apropriando de sua escrita, responsabiliza-se por ela e pelo que ela diz (RODRIGUES, 2011, 2017) e, então, começa a ser agente no próprio processo de mudança de suas práticas docentes.

\section{Considerações finais}

Ao relatar e analisar a experiência de produção de ND por professores de ciências em uma escola de educação básica no sul de Minas Gerais, Brasil, foi oportunizado, em uma via de mão dupla, um processo formativo de professores baseado na construção autoral, com vistas à utilização de tecnologias condizentes com o cenário educacional brasileiro.

Neste caso, a ND surge como uma alternativa para promover um momento de formação atuante e significativa, em que o professor possa aprender com suas próprias experiências, narrando-as e refletindo sobre elas, ao mesmo tempo em que utiliza as TDICs para fazê-lo. Aliada à tecnologia, a ND torna-se uma ferramenta significativa e cativante, como foi observado nesta experiência com os professores, mas que precisa de trabalhos e pesquisas em outros contextos e cenários próprios do cotidiano educacional brasileiro.

Especificamente, esta experiência permitiu identificar a ND como um elemento motivacional no processo de formação continuada de professores, principalmente pela oportunidade de docentes compartilharem suas práticas e, intencionalmente, refletirem sobre elas, o que contribui para sua atuação futura, auxiliando o seu processo de aprendizado, e também indica um favorecimento em prol de seu desenvolvimento profissional. 
Dadas a viabilidade e a acessibilidade para as distintas realidades das escolas brasileiras, com base nas referências encontradas na literatura, por meio deste trabalho, identificou-se um potencial nas NDs para serem utilizadas na formação continuada de professores para o uso pedagógico das TDICs.

Registra-se, ainda, que esta proposta pode ser adaptada às necessidades de cada formação específica, em grupo ou individual, pois ela não se limita a qualquer área específica da atual estrutura escolar brasileira, ou mesmo da internacional, tampouco é excludente em relação à formação com vistas às tecnologias, pois se trata de uma sequência de encontros que pode se constituir como uma capacitação/ formação de professores para o uso de tecnologias, promovendo profundas reflexões sobre as necessidades individuais de formação. Ressalta-se, entretanto, que, para o atendimento mais próximo e efetivo com o formador, dentro das limitações temporais impostas nessas atividades, esta sequência formativa deve ser organizada para um número adequado de professores, que não ultrapasse seis indivíduos por grupo.

\section{The construction of digital storytellings by science teachers: analysis of a technology-mediated training experience}

\section{Abstract}

This paper presents and analyzes four meetings that constituted a training experience focused on the development of digital storytelling by science teachers from a private school in the South of Minas Gerais, Brazil. This formative experience of the production of the digital storytelling was organized in order to promote teacher's reflection on the pedagogical use of Information and Communication Technologies (ICT), starting with the question: "I have a tablet. And now?". The analysis of the meetings of this formative process allowed to identify the digital storytelling as a motivating element and promoter of reflection in the formation of teachers, since the teachers had the opportunity to share their practices with technologies, to reflect on them and sometimes to change them. We also identify in the digital storytelling resulting from this experience the potential of a cognitive resource to be used in the continued formation, but also initial, of teachers, being feasible and accessible to the different realities and contexts of Brazilian schools.

Keywords: Teacher training. Digital narratives. Digital storytelling, information and communication technologies. 


\section{Referências}

ABRAHÃO, Maria Helena Menna Brandão (org.). A aventura (auto) biográfica: teoria e empiria. Porto Alegre: EDIPUCRS, 2004.

ALMEIDA, Maria Elizabeth Bianconcini. Integração currículo e tecnologias: concepção e possibilidades de criação de web currículo. In: ALMEIDA, Maria Elizabeth Bianconcini; ALVES, Robson; LEMOS, Silvana Donadio Vilela (org.). Web currículo: aprendizagem, pesquisa e conhecimento com uso de tecnologias digitais. Rio de Janeiro: Letra Capital, 2014. p. 13-19.

ALMEIDA, Maria Elizabeth Bianconcini. Inclusão digital do professor: formação e prática pedagógica. São Paulo: Articulação, 2004.

ALMEIDA, Maria Elizabeth Bianconcini; VALENTE, José Armando. Narrativas digitais e o estudo de contextos de aprendizagem. Revista de Educação a Distância - Em Rede, Associação Universidade em Rede, v. 1, n. 1, p. 32-50, 2014. Disponível em: http://www.aunirede.org.br/ revista/index.php/emrede/article/view/10. Acesso em: 15 fev. 2019.

ALMEIDA, Maria Elizabeth Bianconcini; VALENTE, José Armando. Integração currículo e tecnologias e a produção de narrativas digitais. Currículo sem Fronteiras, Porto Alegre, v. 12, n. 3, p. 57-82, 2012. Disponível em: http://www.curriculosemfronteiras.org/vol12iss3articles/almeida-valente.pdf. Acesso em: 25 mar. 2019

ALMEIDA, Maria Elizabeth Bianconcini; VALENTE, José Armando. Tecnologias e currículo: trajetórias convergentes ou divergentes? São Paulo: Paulus, 2011.

ARAÚJO, Cristina Freitas Gonçalves de. TV digital e convergência de mídias: estudo exploratório sobre narrativas interativas. 2010. 129 f. Dissertação (Mestrado em Televisão Digital: Informação e Conhecimento) - Universidade Estadual Paulista Júlio de Mesquita Filho, Bauru, SP, 2010. Disponível em: https:/www.faac.unesp.br/Home/Pos-Graduacao/MestradoeDoutorado/TelevisaoDigital/cristiana-freitas-goncalves-de-araujo.pdf. Acesso em: 2 mar. 2019.

BARTHES, Roland. Introdução à análise estrutural da narrativa. In: BARTHES, Roland et al. Análise estrutural da narrativa. 8. ed. Petrópolis: Vozes, 2013. p. 19-62.

BOTTENTUIT JUNIOR, João Batista; LISBÔA, Eliana Santana; COUTINHO, Clara Pereira. Narrativas digitais na formação inicial de professores: um estudo com alunos de licenciatura em pedagogia. Revista Teias, Rio de Janeiro, v. 13, n. 27, p. 191-204, 2012. Disponível em: http:// www.periodicos.proped.pro.br/index.php/revistateias/article/view/894. Acesso em: 21 mar. 2019.

BRASIL. Programa Ensino Médio Inovador: documento orientador. 2013. Disponível em: http:// portal.mec.gov.br/index.php?option=com_docman\&view=download\&alias=13249-doc-orientador-proemi2013-novo-pdf\&category_slug=junho-2013-pdf\&Itemid=30192. Acesso em: 7 dez. 2018.

BRASIL. Ministério distribuirá tablets a professores do ensino médio. 2012. Disponível em: http:// portal.mec.gov.br/ultimas-noticias/215-568057805/17479-ministerio-distribuira-tablets-a-professores-do-ensino-medio. Acesso em: 27 jan. 2019.

BRASIL. ProInfo Integrado. 2009. Disponível em: http://portal.mec.gov.br/secretaria-de-educacao-a-distancia-sp-2090341739/programas-e-acoes?id=13156. Acesso em: 27 jan. 2019.

BRASIL. Parâmetros Curriculares Nacionais. Brasília, DF: MEC/SEF, 1998. 
BRUNER, Jerome. A construção narrativa da realidade. Critical Inquiry, v. 18, n. 1, p. 1-21, 1991. Disponível em: http://www.academia.edu/4598706/BRUNER_Jerome._A_constru\%C3\%A7\%C3\%A3o_narrativa_da_realidade. Acesso em: 15 maio 2019.

BRUNER, Jerome. Realidade mental, mundos possíveis. Porto Alegre: Artes Médicas, 1997.

CARVALHO, Gracinda Souza de. As histórias digitais: narrativas no século XXI - o software Movie Maker como recurso procedimental para a construção de narrações. 2008. $197 \mathrm{f}$. Dissertação (Mestrado em Educação) - Universidade de São Paulo, São Paulo, 2008. Disponível em: http://www.teses.usp.br/teses/disponiveis/48/48134/tde-27082010-104511/publico/Gracinda_Souza_de_Carvalho.pdf. Acesso em: 2 abr. 2019.

CETIC.BR. Educação e tecnologias no Brasil: um estudo de caso longitudinal sobre o uso das tecnologias de informação e comunicação em 12 escolas públicas. 2016. Disponível em: www.cetic. br. Acesso em: 9 abr. 2019.

CHENÉ, Adèle. A narrativa de formação e a formação de formadores. In: NÓVOA, Antonio; FINGER, Mathias (org.). O método (auto)biográfico e a formação. Lisboa: Ministério da Saúde, 1988. p. 89-97.

CLARKE, Robert; ADAM, Andrea. Digital storytelling in Australia: academic perspectives and reflections. Arts and Humanities in Higher Education, v. 11, n. 1-2, p. 157-176, 2012. Disponível em: eric.ed.gov/?id=EJ955497. Acesso em: 12 dez. 2018.

CONNELLY, F. Michael; CLANDININ, D. Jean. Relatos de experiência e investigação narrativa. In: LARROSA, Jorge (org.). Déjame que te cuente. Barcelona: Laertes, 1995. p. 1-26.

ECKERT-HOFF, Beatriz Maria. Escritura de si e identidade: o sujeito-professor em formação. Campinas: Mercado de Letras, 2008.

ESCALANTE, Simone Bordallo de Oliveira. O uso do tablet como resultado de apoio ao processo de ensino e aprendizagem: a percepção de jovens e professores do ensino médio. 2013. $123 \mathrm{f}$. Dissertação (Mestrado em Educação) - Universidade Católica de Brasília, Brasília, DF, 2013. Disponível em: https://bdtd.ucb.br:8443/jspui/handle/tede/1986. Acesso em: 2 abr. 2019.

FARIA, Ádila; FARIA, Paulo; RAMOS, Maria Altina. Interactive Multimodal Narrative as an Approach to Developing Emergent Literacy in Early Childhood Education. Sino-US English Teaching, v. 10, n. 4, p. 328-333, 2013. Disponível em: http://repositorium.sdum.uminho.pt/handle/1822/33714. Acesso em: 12 dez. 2018.

FLICK, Uwe. Introdução à pesquisa qualitativa. 3. ed. Porto Alegre: Artmed, 2009.

FENTY, Nicole S.; ANDERSON, Elizabeth. Creating digital narratives: guideline for early childhood educators. Childhood Education, v. 92, n. 1, p. 58-63, 2016. Disponível em: http://eric. ed.gov/?id=EJ1086121. Acesso em: 3 abr. 2019.

GALVÃO, Cecília. Narrativas em educação. Ciência \& Educação, Bauru, v. 11, n. 2, p. 327-345, 2005. Disponível em: http://www.scielo.br/pdf/ciedu/v11n2/12.pdf. Acesso em: 7 out. 2018.

JONASSEN, David. Computadores, ferramentas cognitivas: desenvolver o pensamento crítico nas escolas. Porto: Editora Porto, 2007.

KENSKI, Vani. Tecnologias e ensino presencial e a distância. São Paulo: Papirus, 2003. 
LOVELL, Sue; BAKER, Sarah. Digital narratives of youth transition: engaging university students through blended learning. Youth Studies Australia, Austrália, v. 28, n. 4, p. 52-59, 2009. Disponível em: http://eric.ed.gov/?id=EJ867260. Acesso em: 2 abr. 2019.

MADDALENA, Tania Lucía; SEVILLA PAVÓN, Ana. El relato digital como propuesta pedagógica em la formación continua de profesores. Revista Iberoamericana de Educación, v. 65, p. 149-160, 2014. Disponível em: rieoei.org/rie65a09.pdf. Acesso em: 29 abr. 2016.

NÓVOA, Antonio (org.). Vidas de professores. 2. ed. Porto: Porto Editora, 2013.

PAIVA, Vera Menezes. Narrativas multimídia de aprendizagem de língua inglesa: um gênero emergente. In: SIMPÓSIO INTERNACIONAL DE ESTUDOS DE GENEROS TEXTUAIS, 4, 2007. Anais... Tubarão: Unisul, 2007. p. 1-22. Disponível em: www.veramenezes.com/narmulting. pdf. Acesso em: 2 jan. 2019.

PASSEGGI, Maria da Conceição. A experiência em formação. Educação, Porto Alegre, v. 34, n. 2, p. 147-156, 2011. Disponível em: http://www.redalyc.org/articulo.oa?id=84819058004. Acesso em: 26 mar. 2019.

PAUL, Nora. Elementos das narrativas digitais. In: FERRARI, Pollyana (org.). Hipertexto, $h i$ permídia: as novas ferramentas da comunicação digital. São Paulo: Contexto, 2007. p. 121-140.

PINEAU, Gaston. As histórias de vida em formação: gênese de uma corrente de pesquisa-ação-formação existencial. Educação e Pesquisa, São Paulo, v. 32, n. 2, p. 329-343, 2006. Disponível em: http://www.scielo.br/pdf/ep/v32n2/a09v32n2.pdf. Acesso em: 30 set. 2018.

REDONDO, Léo Vitor Alves. Características e formatos das narrativas digitais: as narrativas na sociedade da interação. 2010. 118 f. Dissertação (Mestrado em Comunicação) - Universidade Estadual Paulista Júlio de Mesquita Filho, Bauru, 2010. Disponível em: https://repositorio.unesp. br/handle/11449/89499. Acesso em: 30 fev. 2019.

RIBEIRO, Mayra Rodrigues Fernandes; SANTOS, Edméa. Pesquisa formação multirreferencial e com os cotidianos na cibercultura: tecendo a metodologia com um rigor outro. Revista educação pública, v. 25, n. 59, p. 295-310, 2016. Disponível em: http://periodicoscientificos.ufmt.br/ojs/index. php/educacaopublica/article/view/3676/2574. Acesso em: 2 jan. 2019.

ROBIN, Bernard R. Digital Storytelling: a powerful technology toll for the $21^{\text {st }}$ century classroom. Theory Into Pratice, v. 47, n. 3, p. 220-228, 2008. Disponível em: eric.ed.gov/?id=EJ799668. Acesso em: 20 jul. 2018.

ROBIN, Bernard R.; MCNEIL, Sara G. What Educators Should Know about Teaching Digital Storytelling. Digital Education Review, Texas, v. 22, p. 37-51, dez. 2012. Disponível em: eric. ed.gov/?id=EJ996781. Acesso em: 12 jun. 2018.

ROBY, Teshia Young. Opus in the classroom: Striking CoRDS with content-related digital storytelling. Contemporary Issues in Technology and Teacher Education, v. 10, n. 1, p. 133-144, 2010. Disponível em: http://eric.ed.gov/?id=EJ904607. Acesso em: 15 mar. 2019.

RODRIGUES, Alessandra. Narrativas digitais, currículo e autoria na formação de professores mediada pelas tecnologias: uma narrativa-tese. 2017. 274 f. Tese (Doutorado em Educação: Currículo) - Pontifícia Universidade Católica de São Paulo, São Paulo, 2017. Disponível em: https:// tede2.pucsp.br/handle/handle/20196. Acesso em: 1 ago. 2018.

RODRIGUES, Alessandra. Escrita e autoria: entre histórias, memórias e descobertas. Campinas: Mercado de Letras, 2011. 
RODRIGUES, Alessandra; GONÇALVES, Lina Maria. Narrativas digitais na formação de professores: da memória, do registro e do discurso emergem posturas e experiências. Revista Contexto e Educação, Ijuí, v. 29, n. 94, p. 212-237, 2014. Disponível em: https://www.revistas.unijui.edu. br/index.php/contextoeducacao/article/view/3979/4673. Acesso em: 19 dez. 2018.

SOUZA, Elizeu Clementino de (org.). Memória, (auto) biografia e diversidade: questões de método e trabalho docente. Salvador: EDUFBA, 2011.

VALENTE, José Armando. Por quê o computador na educação? [1995?]. Disponível em: http:// www.mrherondomingues.seed.pr.gov.br/redeescola/escolas/27/1470/14/arquivos/File/PPP/TextoComputadornaEducacao.pdf. Acesso em: 27 nov. 2018.

VASCONCELOS, Dennise Cunha de; MAGALHÃES, Henrique. As Narrativas Multimediáticas das Charges Animadas. Cultura Mediática, v. 3, n. 1, p. 1-10, 2010. Disponível em: http://periodicos.ufpb.br/ojs/index.php/cm/article/view/11721. Acesso em: 29 mar. 2019.

WESTON, Mark E.; BAIN, Alan. The end of techno-critique: the naked truth about 1:1 laptop initiatives and educational change. Journal of Technology, Learning and Assessment, v. 9, n. 6, p. 5-24, 2010. Disponível em: http://ejournals.bc.edu/ojs/index.php/jtla/article/view/1611. Acesso em: 10 abr. 2019.

XIN, Joy F. Digital stories in writing instruction for middle school students with autism. CSCanada: Studies In Literature and Languages, Quebec, v. 9, n. 1, p. 1-10, 2014. Disponível em: http:// www.cscanada.net/index.php/sll/article/view/5180/6211. Acesso em: 9 abr. 2019.

ZABALZA, Miguel. Diários de aula: um instrumento de pesquisa e desenvolvimento profissional. Porto Alegre: Artmed, 2008. 